SMALL INTESTINE

\title{
Enteropathy precedes type 1 diabetes in the $B B$ rat
}

\author{
S Graham, P Courtois, W J Malaisse, J Rozing, F W Scott, A Mc I Mowat
}

Gut 2004;53:1437-1444. doi: 10.1136/gut.2004.042481

See end of article for authors' affiliations

......................

Correspondence to: Professor A Mowat, Department of Immunology and Bacteriology, University of Glasgow, Western Infirmary, Glasgow G1 1 6NT, UK; a.m.mowat@ clinmed.gla.ac.uk

Received

24 February 2004

Accepted for publication 16 March 2004

\begin{abstract}
Background and aims: There is increasing evidence implicating intestinal immune responses to dietary proteins in the pathogenesis of type 1 autoimmune diabetes (TID). Here we investigated the association between intestinal pathology and dietary factors in TID by examining the mucosal architecture in the BB rat model.

Methods: $\mathrm{BB}$ control $(\mathrm{BBC})$ and diabetes prone $(\mathrm{BBdp})$ rats were fed either a diabetes retardant hydrolysed casein based diet or one of two cereal based diets that promote the development of diabetes. Intestinal architecture was assessed in the jejunum by microdissection, histology, and immunohistology, and by measuring peroxidase activity and brush border invertase levels.

Results: Enteropathy was present in BBdp rats soon after weaning, as assessed by increases in crypt length and in the proliferative activity of crypt epithelial cells in the jejunum, and this remained constant until 120 days of age. There was also a decrease in invertase activity, as well as increased numbers of intraepithelial lymphocytes, increased levels of mucosal peroxidase activity, and infiltration of the mucosa by $\mathrm{CD}^{+} \mathrm{T}$ lymphocytes. Equivalent enteropathy was present at all times in $\mathrm{BBdp}$ rats and was not influenced by the nature of the diet or by thymectomy at three weeks at age, procedures which prevent the development of diabetes.

Conclusion: Enteropathy is a consistent feature in the diabetes prone BB rat but it precedes the onset of insulitis and appears to be due to mechanisms distinct from those which cause diabetes. The beneficial effects of the diabetes retardant hydrolysed casein diet on diabetes are not due to an effect on intestinal architecture per se but mucosal damage may be necessary for the development of autoreactivity in the pancreas.
\end{abstract}

$\mathrm{T}$ ype 1 diabetes (TID) is associated with autoimmune destruction of the insulin producing $\beta$ cells in the pancreatic islets due to a genetically determined breakdown in self tolerance. Although susceptibility to T1D is tightly linked to multiple genes of MHC and non-MHC origin, environmental factors also play an important role. ${ }^{12}$ One of these factors is diet, and we and others have shown that the incidence of spontaneous diabetes in BB rats ${ }^{2-5}$ or NOD mice ${ }^{6-9}$ is decreased in animals fed a diet containing hydrolysed casein or other diabetes retardant amino acid sources.

One way in which diet could influence diabetes is that an aberrant immune response to dietary proteins somehow predisposes to the autoimmune response that develops against pancreatic $\beta$ cells. This is supported by the fact that $\mathrm{T}$ cells from some humans with TID show unusually high reactivity to the gluten component of wheat protein. ${ }^{11} \mathrm{~A}$ similar situation occurs in coeliac disease where aberrant $\mathrm{T}$ cell responses to gluten lead to severe damage to the small intestine, characterised by villus atrophy, crypt hyperplasia, and ultimately malabsorption. Interestingly, there is a higher than normal incidence of overt coeliac disease in patients with TID, with $2-10 \%$ (or more) of patients having histological evidence of gluten sensitive enteropathy. ${ }^{12-15}$ In addition, approximately $10 \%$ of DQ2 homozygous T1D patients have circulatory IgA autoantibodies against tissue transglutaminase $(\mathrm{tTG})^{16}$ and a further $30 \%$ have circulating IgG anti-tTG autoantibodies. ${ }^{17}$ Together with the fact that TID and coeliac disease share overlapping susceptibility genes, ${ }^{15}{ }^{18}$ in particular the HLA DQBI ${ }^{*} 0201$ allele, ${ }^{19}$ these features are consistent with the idea that diet related immune responses in the gut could be important factors in the pathogenesis of diabetes. This is also supported by evidence that patients with $\mathrm{TlD}^{20}$ and $\mathrm{BB}$ diabetes prone rats ${ }^{21}$ both have increased gut permeability and may show abnormal immune reactivity against a wheat storage globulin protein, ${ }^{11}$ while the inflamed pancreas in NOD mice ${ }^{22-24}$ displays aberrant expression of MADCAM-1, a vascular adhesion molecule normally restricted to mucosal tissues. In parallel, $\mathrm{T}$ cells bearing the $\alpha_{4} \beta_{7}$ integrin, the ligand for MAdCAM-1, migrate to the pancreas of NOD mice, ${ }^{25}$ and blocking $\alpha_{4} \beta_{7}$ or MAdCAM-1 in vivo prevents islet cell damage. ${ }^{26}$ Diabetic patients also have a population of islet cell antigen reactive lymphocytes that express the $\alpha_{4} \beta_{7}$ integrin. $^{27}$

It is therefore important to determine the exact nature of the relationship between gut damage, immune responses to dietary proteins, and diabetes. As a first step towards this aim, here we have examined for the presence of enteropathy in $\mathrm{BB}$ control $(\mathrm{BBC})$ and diabetes prone $(\mathrm{BBdp})$ rats and have determined the effects of diets with different diabetes inducing potential.

\section{MATERIALS AND METHODS}

\section{Animals}

Male and female diabetes prone BioBreeding (BBdp) and control $\mathrm{BB}$ rats $(\mathrm{BBC})$ used in the dietary studies were obtained from the Animal Resources Division of Health Canada (Ottawa, Canada). For the thymectomy experiments, diabetes prone BB (BBDP/Gro) and diabetes resistant (BBDR/ Gro) rats obtained originally from the University of Massachusetts (Worcester, Massachusetts, USA) were bred at the central animal facility of the University of Groningen. All animals were raised under specific pathogen free conditions and weaned at 23 days of age. Animals were given free access to food and water. Experiments were

Abbreviations: TID, type 1 autoimmune diabetes; $B B C, B B$ control rats; $B B d p, B B$ diabetes prone rats; $\mathrm{TTG}$, tissue transglutaminase; WG, wheat gluten; HC, hydrolysed casein; CCPR, crypt cell production rate; IEL, intraepithelial lymphocytes; DC, dendritic cell 
approved by the Animal Care Committees at each institution and the principles of laboratory animal care were observed, as described by the Canadian Council on Animal Care or the Dutch law on the use of experimental animals.

\section{Diets}

In the animal studies performed in Ottawa, rats were fed an NTP-2000 diet (NTP) (Zeigler Bros., Gardners, Pennsylvania, USA) that is mainly plant based (milk free) with wheat as the major component (37\%), and containing approximately $14.6 \%$ protein, $8.2 \%$ fat, $9.9 \%$ crude fibre, $52 \%$ carbohydrate, and $10.7 \%$ moisture. The diet was irradiated before use and contained low levels of chemical and microbial contaminants. ${ }^{28}$ Two isocaloric and isonitrogenous semi purified test diets were used: a wheat gluten (WG) diet consisting of $22.5 \%$ wheat gluten (ICN Biochemicals, Cleveland, Ohio, USA) and a hydrolysed casein (HC) diet containing 20.0\% casein hydrolysate (pancreas $\mathrm{S}$ enzymatic hydrolysate; Sensient Flavors Canada Inc., Mississauga, Ontario, Canada) as a source of amino acids. For the studies performed on thymectomised rats in Groningen, rats were fed a standard cereal based rodent diet (Hope Farms, rodent diet No Rmh-B2181; Woerden, the Netherlands).

\section{Assessment of intestinal architecture}

The method of Clarke was used, as described previously. ${ }^{29} 30$ Briefly, pieces of jejunum $10 \mathrm{~cm}$ from the pylorus were fixed in $75 \%$ ethanol and $25 \%$ glacial acetic acid, and stained with Schiff reagent (Sigma Chemical Co., St Louis, Missouri, USA). Using a dissecting microscope, sections one villus/crypt unit thick were cut and villus and crypt lengths determined using an eyepiece micrometer. Ten villi and crypts were measured in each section. Tissues were then gently squashed under the coverslip and the number of mitotic bodies per crypt was determined. In some experiments, crypt cell production rates (CCPR) were measured by injecting rats intraperitoneally with $7.5 \mathrm{mg} / \mathrm{kg}$ body weight of colchicine and samples of jejunum were collected 30-90 minutes later. Metaphases were counted for each time point and the mean number of metaphases per crypt was calculated and plotted against the time after colchicine injection. CCPR was calculated from the gradient of the line.

\section{Assessment of the density of intraepithelial lymphocytes (IEL)}

IEL were counted on paraffin embedded haematoxylin-eosin stained sections of jejunum and were expressed as the mean number of IEL per 100 epithelial cells. A total of 600 epithelial cells were counted in each sample.

\section{Measurement of intestinal invertase and peroxidase activities}

A 1-2 cm segment of proximal jejunum was homogenised in $3 \mathrm{ml}$ of cold distilled water and frozen immediately. After thawing and ultrasonication on ice, invertase activity was measured using a two step method. ${ }^{31}$ Samples were first incubated with [U- $\left.{ }^{14} \mathrm{C}\right]$ sucrose (NEN Life Science Products, Boston, Massachusetts, USA) in $100 \mu \mathrm{l}$ aliquots of HEPES$\mathrm{NaOH}$ buffer $(50 \mathrm{mmol} / \mathrm{l}, \mathrm{pH}$ 6.5) containing $6 \mathrm{mmol} / \mathrm{l}$ $\mathrm{MgCl}_{2}, 60 \mathrm{mmol} / \mathrm{l} \mathrm{KCl}$, and $10 \mathrm{mmol} / \mathrm{l} \mathrm{KH}_{2} \mathrm{PO}_{4}$ for $15 \mathrm{~min}$ utes at $30^{\circ} \mathrm{C}$. The reaction was stopped by heating at $85^{\circ} \mathrm{C}$ for 10 minutes and the release of labelled products $\mathrm{D}-\left[\mathrm{U}-{ }^{14} \mathrm{C}\right]$ glucose and $\mathrm{D}-\left[\mathrm{U}-{ }^{14} \mathrm{C}\right]$ fructose was measured. These were first phosphorylated in $500 \mu \mathrm{l}$ aliquots by incubation for two hours at $37^{\circ} \mathrm{C}, \mathrm{pH} 7.5$, with $3.6 \mathrm{U} / \mathrm{ml}$ yeast hexokinase (Roche, Mannheim, Germany) and $3.2 \mathrm{mmol} / \mathrm{l} \mathrm{ATP}$, separated by ion exchange chromatography, and the amount of radiolabelled products counted by liquid scintillation. All measurements were made in triplicate.
As described previously, ${ }^{32}$ peroxidase activity was measured at $30^{\circ} \mathrm{C}$ in tissue homogenates diluted $1: 1$ in $0.006 \%$ Triton, freeze-thawed $(3 \times)$ in a dry ice/acetone bath, that were sonicated on ice, using a spectrophotometer, by mixing $100 \mu \mathrm{l}$ of sample with $3.4 \mathrm{ml}$ acetate buffer $(50 \mathrm{mmol} / \mathrm{l}, \mathrm{pH}$ 5.4) containing $0.3 \mathrm{M}$ sucrose, $1.4 \mathrm{mmol} / \mathrm{l}$ tetramethylbenzidine (Sigma), and $300 \mu \mathrm{M}$ hydrogen peroxide (Merck, Darmstadt, Germany). Change in absorbance at $655 \mathrm{~nm}$ was measured and 1 unit of peroxidase activity was defined as 1 absorbance unit increase per minute under linear conditions.

\section{Thymectomy}

BBDP/Gro and BBDR/Gro rats were thymectomised at three weeks of age, as described previously. ${ }^{33}$ Completeness of thymectomy was verified by the absence of circulating thymic migrants in peripheral blood and by anatomical inspection at necropsy. Control rats were subjected to sham thymectomy at the same age.

\section{Immunohistochemistry}

Sections of small intestine $(6-8 \mu \mathrm{m})$ were cut and mounted on to poly-L-lysine coated microscope slides which were air dried and stored at $-20^{\circ} \mathrm{C}$ until required. Sections were brought to room temperature and fixed in $100 \%$ ethanol for 15 minutes. Endogenous peroxidase activity was quenched by three changes of $3 \% \mathrm{H}_{2} \mathrm{O}_{2}$ and $0.1 \% \mathrm{NaN}_{3}$ in phosphate buffered saline for five minutes before blocking with an avidin-biotin blocking kit (Vector, Burlingame, California, USA). Sections were then incubated with purified anti-CD4 (OX-38), purified anti-CD8 (OX-8), purified anti-CD45R (HIS24), or $\alpha_{\mathrm{E}}$ integrin (OX-62), all diluted 1:100, or with FITC conjugated anti-RT1B (OX-6) diluted 1:200 (all from PharMingen, Cowley, Oxon, UK) for 60 minutes. Antibody dilutions were made in a $0.1 \%$ bovine serum albumin BSA. T cell receptor $\alpha \beta$ was detected using a supernatant containing the purified antibody which was a kind gift from Lesley Cousins (Sir William Dunn School of Pathology, Oxford, UK). Purified antibodies were amplified using the TSA Biotyn System (PerkinElmer Life Sciences, Wellesley, Massachusetts, USA) according to the manufacturer's protocol and visualised using streptavidin Alexa Fluor 488 or 647 (Molecular Probes, Paisley, UK). Slides were mounted in Vectorshield containing DAPI (Vector). Colour images of the tissue sections were captured using a Hamamatsu Orca ER Digital CCD camera attached to an Olympus BX50 microscope and were then processed using Openlab 3.1 software (Improvision, UK).

\section{Statistical analysis}

Comparisons between groups were performed using a one way ANOVA, Student's $t$ test, or the Wilcoxon rank sum test. CCPR were compared using covariance analysis; $p$ values less than 0.05 were considered significant.

\section{RESULTS}

\section{Influence of diet on diabetes}

The mean incidence of diabetes in BBdp rats in the Ottawa colony fed the standard NTP diet has remained constant over the past five years (mean 65.3 (SD 14.9)\%; total of 169 rats). ${ }^{11}$ Rats fed the WG diet have a similar incidence of diabetes (50.6 (11.1)\%, $\mathrm{n}=282$ ) whereas those fed the HC diet are protected from diabetes to a considerable extent (18.8 (10.6)\%; $\mathrm{n}=322 ; \mathrm{p}<0.001)$.

\section{Development of enteropathy in diabetes prone rats}

Mucosal architecture was measured in BBC and BBdp rats from day 10 until 120 days of age. This spectrum covers the time before weaning, the period before classic insulitis, and 

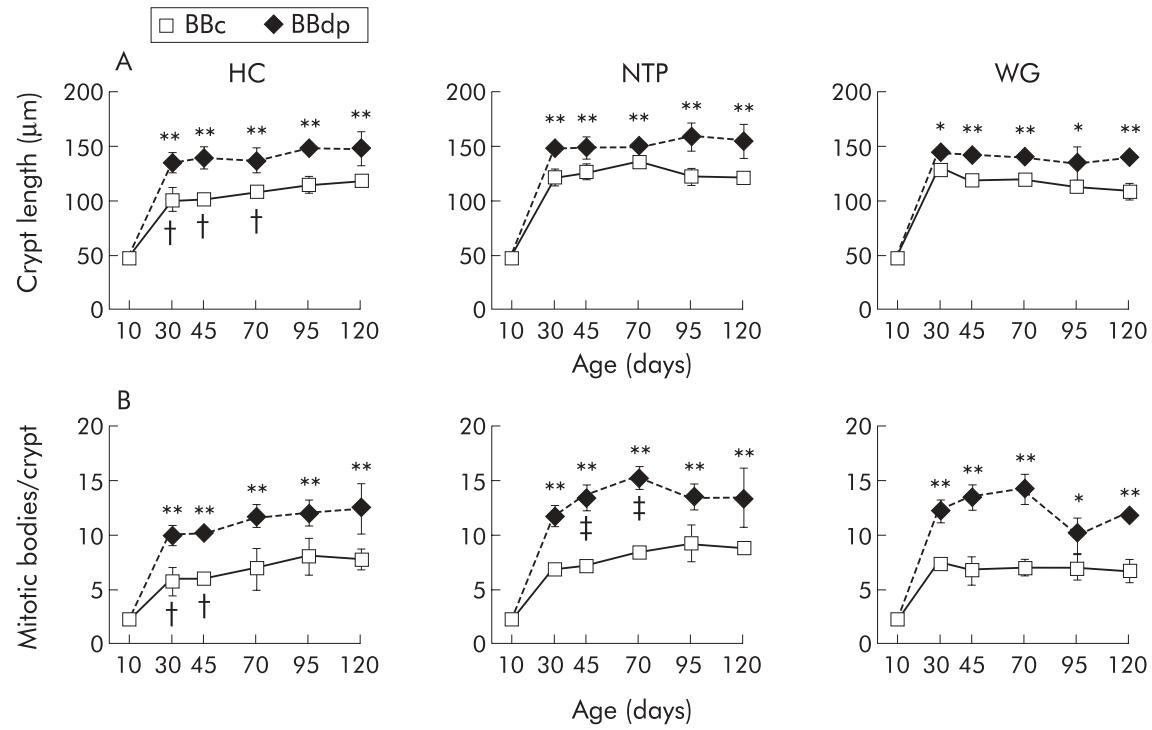

Figure 1 Diet and enteropathy in the BB rat. Mucosal architecture in the jejunum of $B B$ diabetes prone (BBdp) and control (BBC) rats fed diabetes promoting (NTP, wheat gluten (WG)) or protective (hydrolysed casein (HC)) diets, assessed by crypt length (A) and number of mitotic figures in the crypts (B). Samples of jejunum were analysed by microdissection from 10-120 days of age and the results shown are means (SD) for BBC and BBdp rats. ${ }^{*} p<0.05,{ }^{* *} p<0.01, B B c$ versus $B B d p ; \uparrow p<0.05, B B c$ rats fed $H C$ diet versus $B B c$ rats fed NTP diet; $\neq p<0.05, B B d p$ fed $H C$ diet versus $B B d p$ fed NTP diet (5-8 rats/group).

the beginning of insulitis at approximately 50 days of age, until the appearance of clinical diabetes, between 60 and 120 days.

Significant enteropathy was present in the jejunum of BBdp rats fed the diabetes promoting WG and NTP diets at all times from 30 days of age onwards (figs 1, 3). The pathology consisted of marked crypt lengthening and increased numbers of mitotic bodies compared with the equivalent values in age matched BBc. All aspects of mucosal architecture were normal in BBdp rats examined before weaning at 10 days of age but after crypt hypertrophy and hyperplasia had appeared, these features remained constant until the experiment finished at 120 days. Increases in crypt length and mitotic activity were seen between days 10 and 30 in all rats, including BBc rats, features consistent with the physiological effects of weaning on intestinal maturation. ${ }^{30}$ BBdp rats fed the WG diet also had generally reduced villus lengths compared with controls throughout the study but this was not statistically significant, except at 10 days of age (fig 2). NTP fed BBdp rats also had significant villus shortening at this time but this was not seen at other time points.

A further early indicator of immunologically mediated enteropathy in the small intestine is an increased density of IELs. ${ }^{34}$ To examine if this also occurred in the BBdp rat, separate groups of BBdp and $\mathrm{BBC}$ rats were examined at the earliest time point when enteropathy was apparent (day 30 ). At this time, BBdp rats had a significant increase in the number of IEL in the jejunum compared with BBc controls (fig 4A).

Immunohistological analysis of jejunal sections taken from $\mathrm{BBc}$ rats on day 70 showed the expected pattern of lymphoid cells, with $\mathrm{CD}^{+}$cells in the lamina propria and $\mathrm{CD}^{+}$cells in both the lamina propria and epithelium (fig 5). Staining for the $\alpha \beta$ T cell receptor confirmed that these $\mathrm{CD} 4^{+}$and $\mathrm{CD} 8^{+}$ cells were T cells (data not shown). In addition, class II $\mathrm{MHC}^{+}$ cells were abundant in the lamina propria and double staining for the $\alpha_{\mathrm{E}}$ integrin indicated that many of these were dendritic cells (DCs) (fig 5). In comparison, BBdp rats fed the NTP diet had markedly increased infiltration of the

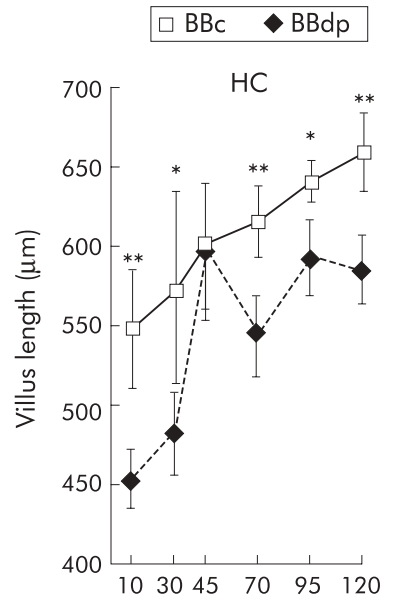

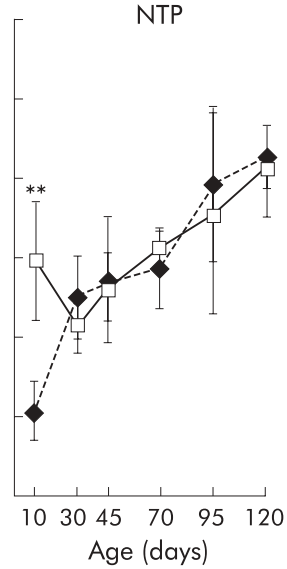

WG

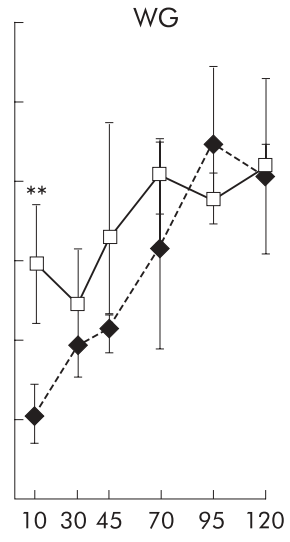

Figure 2 Diet and enteropathy in the $B B$ rat. Villus length in the jejunum of $B B$ diabetes prone (BBdp) and control (BBC) rats fed diabetes promoting (NTP, wheat gluten (WG)) or protective (hydrolysed casein $(\mathrm{HC})$ ) diets. Samples of jejunum were analysed by microdissection from 10-120 days of age. The results shown are means (SD) for $B B C$ and $B B d p$ rats. ${ }^{*} p<0.05$, ${ }^{* *} p<0.01, B B c$ versus $B B d p(5-8$ rats per group). 

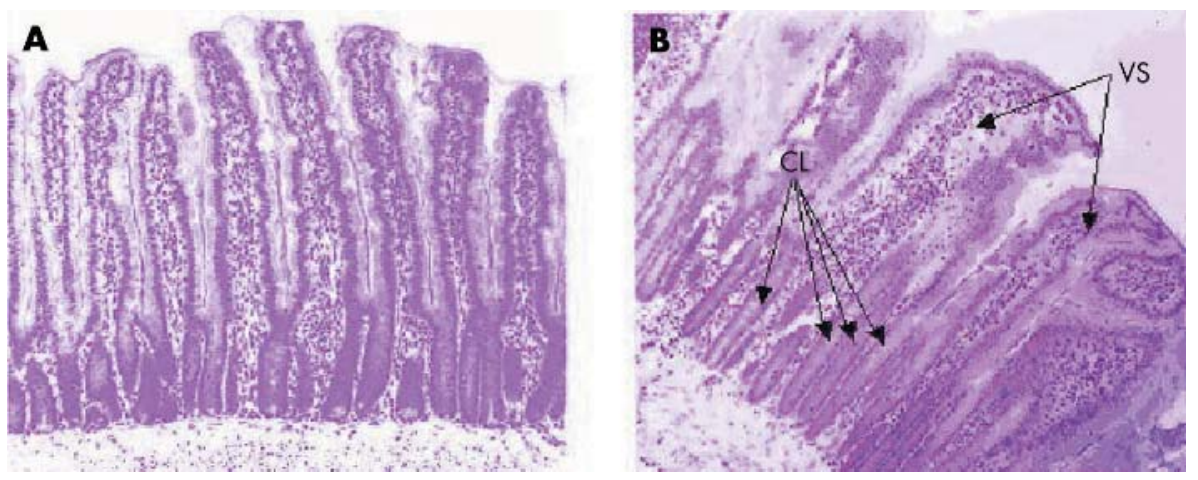

Figure 3 Enteropathy in $B B$ diabetes prone (BBdp) rats. Histological appearance of the jejunum from $(A)$ control (BBC) and (B) BBdp 100 day old rats fed the NTP diet, showing crypt lengthening $(\mathrm{CL})$ and villus shortening (VS) (haematoxylin-eosin $\times 100$ ).

lamina propria by $\mathrm{CD} 4^{+} \mathrm{T}$ cells but a virtual absence of $\mathrm{CD} 8^{+} \mathrm{T}$ cells and of class II MHC ${ }^{+}$cells. $\alpha_{\mathrm{E}}$ integrin expressing cells were present in BBdp mucosa, but in reduced numbers compared with $\mathrm{BBC}$, suggesting a deficiency of total DC numbers. There was a complete lack of class II MHC expression by these cells (fig 5). No class II MHC expression was found in the epithelium of any rat.

The presence of intestinal inflammation in diabetes prone rats was underlined by an increase in the activity of the peroxidase enzyme associated with phagocytic cells. This was
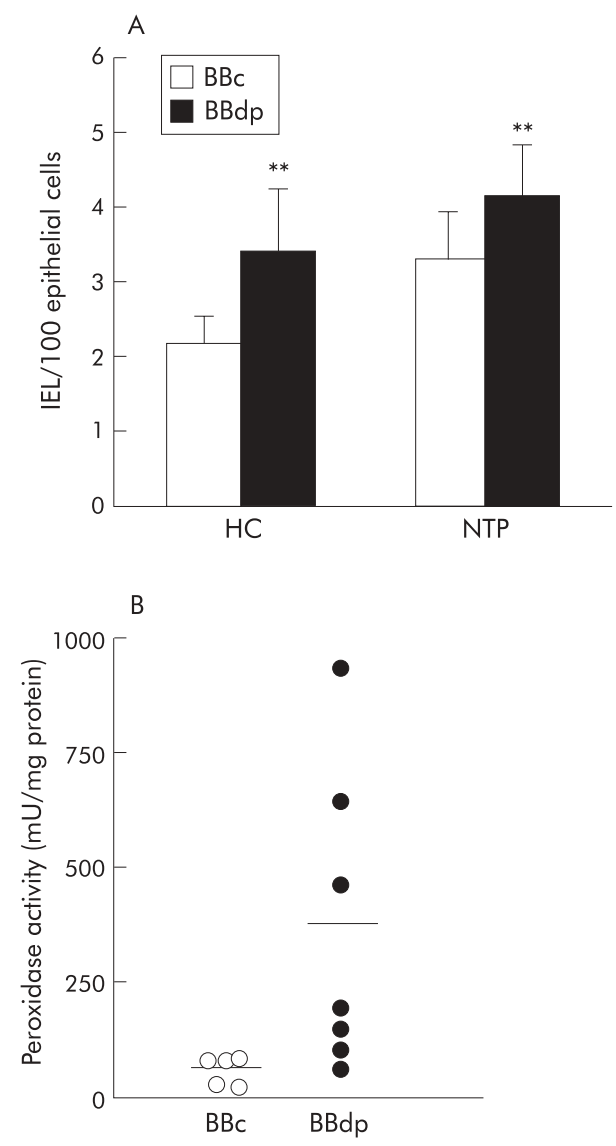

Figure 4 Diet and enteropathy in the BB rat. (A) Intraepithelial lymphocyte (IEL) counts in $\mathrm{BB}$ diabetes prone (BBdp) and control (BBC) rats fed diabetes promoting (NTP) or protective (hydrolysed casein (HC)) diets. Sections of jejunum were stained with haematoxylin-eosin and the number of IELs per 100 epithelial cells was counted $\left({ }^{* *} p<0.01 \mathrm{BBC}\right.$ versus $B B d p)$. (B) Peroxidase activity in the proximal gut of $B B C$ and $B B d p$ rats fed a diabetes promoting NTP diet and sacrificed at 95 days of age. Results shown are the means (SD) of 5-7 rats/group. seen by day 30 (data not shown) and was even more marked by day 95 when BBdp rats had a sevenfold increase in levels of duodenal peroxidase compared with BBc controls (fig 4B; mean 362.3 (SEM 126.3) v 50.6 (13.8) mU/mg; p $<0.02$ Wilcoxon rank sum test). Together, these results indicate that there is an immunologically mediated enteropathy in diabetes prone $\mathrm{BB}$ rats.

\section{Effects of diet on diabetes associated enteropathy}

To explore whether these measures of enteropathy in BBdp rats were influenced by diets with different diabetes promoting potential, we compared indices of mucosal architecture in rats fed the protective HC diet with those fed the NTP or WG diets. Mucosal architecture in BBC rats was markedly influenced by the composition of the diets as throughout the study, animals fed the HC diet had significantly smaller crypts and generally lower CCPRs than $\mathrm{BBC}$ rats fed the NTP and WG diets (fig 1). In contrast, the nature of the weaning diet had little or no effect on the development of enteropathy in BBdp rats. As with rats fed the NTP or WG diets, significant increases in crypt length and mitotic activity were found in BBdp rats fed the protective HC diet compared with their equivalent controls at all times after day 30 (fig 1). Furthermore, there were no differences in villus length in BBdp rats fed a diabetes promoting or protective diet (fig 2), or in the immunohistological changes in $\mathrm{CD}^{+} \mathrm{T}^{-}$cells, $\mathrm{CD}^{+} \mathrm{T}$ cells, or class II $\mathrm{MHC}^{+}$cells seen in BBdp rats (fig 5).

\section{Enteropathy in diabetic rats is associated with functional abnormalities in epithelial enzymes}

To determine whether the enteropathy in BBdp rats also produced functional changes in the intestine and if these were influenced by diet, we measured levels of brush border invertase activity.

In $\mathrm{BBc}$ rats, duodenal invertase activity showed a sharp rise between day 10 and 30 and a late decrease between days 95 and 120, irrespective of diet (fig 6). At day 10, no significant difference in invertase activity was observed between BBC and BBdp rats but from day 30 onwards, invertase levels were consistently lower in BBdp rats fed the diabetes promoting NTP and WG diets or the protective HC diets than in equivalent $\mathrm{BBC}$ rats. These differences were statistically significant at days 30 and 70 in rats fed the NTP or HC diet and at day 70 in animals fed the WG diet (fig 6). No significant differences were found between invertase activity in BBc rats fed the HC diet and those fed either the NTP or WG diet at any time.

\section{Effects of thymectomy on enteropathy and diabetes in BB rats}

To examine the relationship between diabetes and enteropathy further, we used high incidence BBDP/Gro rats: 


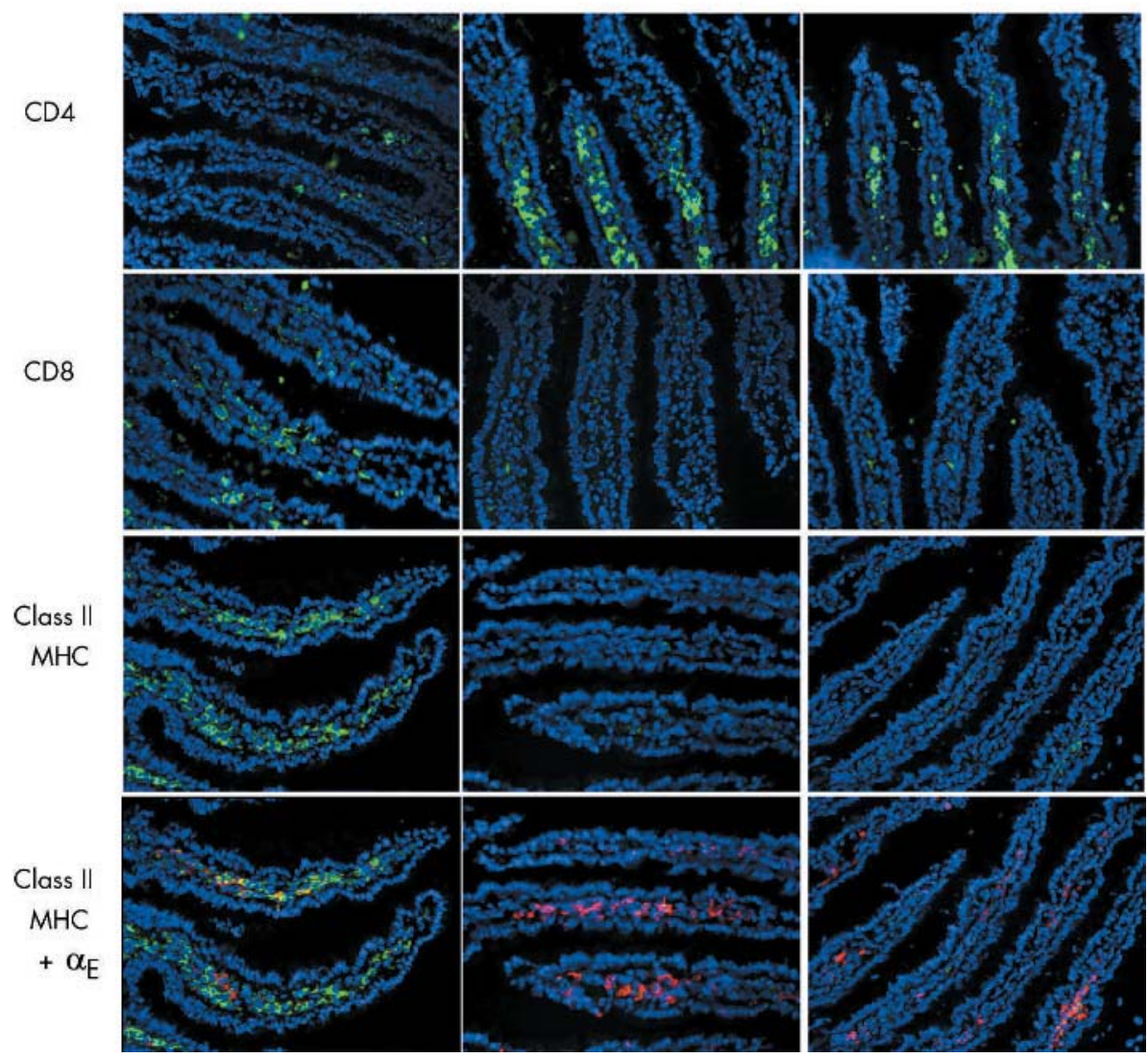

Figure 5 Diet and enteropathy in the BB rat. Immunohistological appearance of the jejunum in 70 day old BB diabetes prone (BBdp) and control (BBC) rats fed hydrolysed casein $(\mathrm{HC})$ and NTP diets. Frozen sections were stained for $\mathrm{CD} 4^{+}, \mathrm{CD} 8^{+}$, and class II $\mathrm{MHC}^{+}$cells using Alex Fluor 488 (green) and for $\alpha_{E}$ integrin using Alex Fluor 647 (red). Nuclei were stained with DAPI (blue) ( $\times 200$ magnification).

90-95\% of these rats fed a standard cereal based diet develop TlD by the age of 10-14 weeks, with histological insulitis being observed from approximately eight weeks. The incidence of diabetes in these animals is reduced to $<5 \%$ by thymectomy at three weeks of age $\mathrm{e}^{35}$ and we therefore examined the effects of thymectomy on enteropathy. Mucosal architecture was measured in thymectomised and sham thymectomised BBDP/Gro or BBDR/Gro rats during the prediabetic phase (day 59) and around the time of onset of diabetes on day 84. Medium to severe insulitis was observed in BBDP/Gro examined at 84 days but no insulitis was found in any of the thymectomised BBDP/Gro rats examined at 59 and 84 days nor in any of the control BB rats (data not shown).

As in the Ottawa colony, sham thymectomised BBDP/Gro rats developed enteropathy during the prediabetic period, with significant crypt hypertrophy compared with BBDR/Gro controls on day 59 (fig 7). On day 84, there was also an
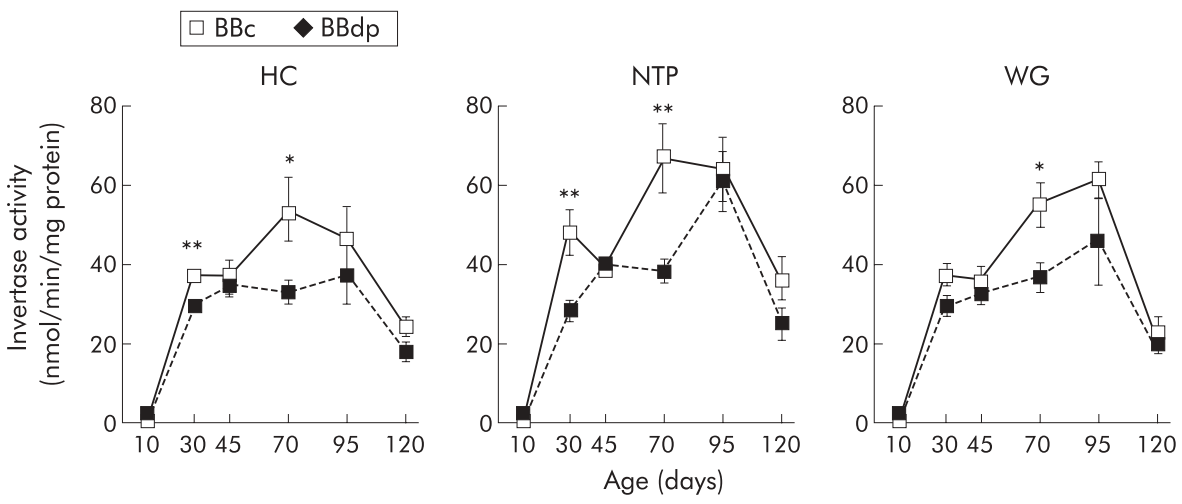

Figure 6 Diet and enteropathy in the BB rat. Invertase activity in the proximal gut of $B B$ diabetes prone (BBdp) and control (BBC) rats fed NTP, wheat gluten (WG), or hydrolysed casein (HC) diets, determined as described in material and methods. The results shown are means (SEM) for 12 rats per group on day 10, and 3-5 per group for each remaining time point $\left({ }^{*} p<0.05,{ }^{* *} p<0.01\right)$. 

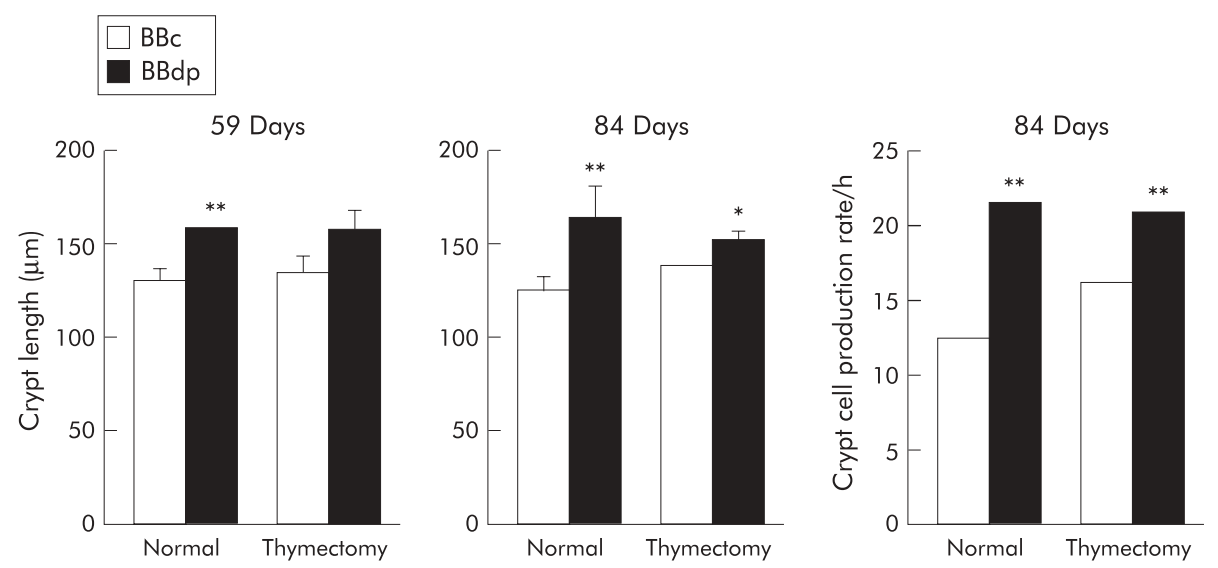

Figure 7 Effects of thymectomy on enteropathy in the $B B$ rat. $B B$ diabetes prone (BBdp) and control $(B B C)$ rats were thymectomised or sham thymectomised at three weeks of age and mucosal architecture was assessed by measurements of crypt length and crypt cell production rate at 59 and 84 days. ${ }^{*} p<0.05,{ }^{* *} p<0.01, B B c$ versus BBdp. Results shown are means (SD) for four rats/group.

increase in CCPR, as measured by a metaphase arrest technique. A similar pattern of intestinal pathology was observed in thymectomised BBDP/Gro rats, with significant increases in crypt length on both days 59 and 84 . Thymectomy had no effect on mucosal architecture in BBDR/Gro control rats. Thus thymectomy had no effect on enteropathy despite its ability to modify diabetes outcome in $\mathrm{BBDP} /$ Gro rats.

\section{DISCUSSION}

The results of this study show that enteropathy is a consistent feature of the BB rat model of TID but indicate that this is not influenced by the complexity of the diet. Enteropathy in diabetes prone BB rats consisted of crypt hypertrophy and hyperplasia, as well as an increase in the proportion of IELs, a decrease in brush border enzyme activity, and increased infiltration of the mucosa by $\mathrm{CD} 4^{+} \mathrm{T}$ cells. Furthermore, the activity of peroxidase was higher in the duodenal mucosa of BBdp rats compared with that of control rats. These features are characteristic of immunologically mediated pathologies in the small intestine, specifically those involving $\mathrm{T}$ cells, including coeliac disease, ${ }^{34}$ parasite infections, ${ }^{36}$ the early stages of Crohn's disease and intestinal graft versus host disease. ${ }^{37} 38$ In these cases, tissue damage is believed to be caused mainly by cytokines such as interferon $\gamma$ and/or tumour necrosis factor $\alpha$ released during a local $\mathrm{CD} 4^{+} \mathrm{T}$ cell mediated immune response. ${ }^{37}$ 39-41 Although the features of the enteropathy we found in BBdp rats were similar to those seen in coeliac disease, villus atrophy was not a marked feature in $\mathrm{BB}$ rats and more dramatic increases in IEL numbers are usually seen in coeliac patients. ${ }^{34}$ This could suggest that the enteropathy in TID is simply a less severe form of the same type of immunopathology. However, it should be noted that once present, the enteropathy did not seem to progress to more severe pathology in the BB rats, as might be expected if it simply represented an early stage in a continuum of disease. Therefore, it may reflect a distinct, if overlapping, set of mechanisms.

As the coeliac disease-like enteropathy that occurs in humans with TID has only been reported in patients with established diabetes, the cause and effect relationship between the two conditions has been uncertain. Our results showed that crypt hypertrophy and hyperplasia appeared between 10 and 30 days of life in BBdp rats, then remained constant for the remainder of the study. As the animals did not develop clinical diabetes until after $\sim 60$ days of age, our findings indicate that the enteropathy is not merely a side effect of diabetes. Furthermore, enteropathy was seen in thymectomised BBdp rats that did not go on to develop insulitis or clinical diabetes, further eliminating the metabolic effects of diabetes as the causative agent of the gut abnormalities. In an attempt to explain these findings, we initially hypothesised that an aberrant $\mathrm{T}$ cell response to dietary protein antigen could be responsible for the enteropathy, which in turn would be a prerequisite for diabetes development. The beneficial effects of low antigen diets that $\mathrm{we}^{21142}$ and others ${ }^{4-9}$ have found in TID would also be consistent with this idea. Furthermore, using a wheat cDNA expression library, we have recently identified a wheat storage globulin, Glbl, that is recognised by antibodies from diabetic BBdp rats and which shares homology with tight junction proteins from the intestinal epithelium. ${ }^{11}$ Feeding a hydrolysed casein based diet inhibited the appearance of clinical diabetes compared with rats fed more complex, mainly wheat based, diets. In addition, the mucosal architecture in control rats fed hydrolysed casein was less mature than in rats fed the other diets. However, the protective diet had no effect on enteropathy in BBdp rats, indicating that the effects of diet on diabetes are not related to an ability to prevent enteropathy per se.

The antigenic stimulus for intestinal pathology remains unknown. One possibility could be that a local immune response against commensal bacteria leads to intestinal pathology, as occurs in experimental models of inflammatory bowel disease. ${ }^{43}$ However, enteropathy in BBdp rats and humans with TID is mainly in the upper small intestine where bacteria are rare. Conversely, tissue damage in models of inflammatory bowel disease that require commensal bacteria is restricted to the colon. ${ }^{43}$ An alternative explanation is that there is an immune response against a self antigen that is shared by both the gut and pancreas. However, thymectomised BBDP rats developed enteropathy in the absence of insulitis, indicating that the intestinal pathology does not require an autoimmune response against the pancreatic islet. In addition, although the pancreas is derived from the embryonic gut during development, no specific cross reacting tissue antigen of this kind has been identified. Some diabetic patients have antibodies against tissue transglutaminase, an autoantigen which is implicated in coeliac disease and which could also be expressed in the pancreas. ${ }^{44}$ However, production of these antibodies is entirely dependent on the presence of gluten in the diet and therefore this type of response should be related to the composition of the diet, which was not the case for enteropathy in BBdp rats. 
Our experiments on thymectomised BB rats demonstrate that different effector mechanisms are responsible for the enteropathy and diabetes. TID is now considered to occur because a defect in regulatory lymphocyte activity permits autoreactive $\mathrm{CD} 4^{+}$and $\mathrm{CD} 8^{+} \mathrm{T}$ cells to infiltrate and damage the islet. ${ }^{45}$ Thymectomy at three weeks of age prevents diabetes from developing in $\mathrm{BB}$ rats due to removal of effector $\mathrm{CD}^{+} \mathrm{T}$ cells but enteropathy was still present in these animals. In addition, immunohistological analysis revealed that $\mathrm{CD}^{+} \mathrm{T}$ cells and class II $\mathrm{MHC}^{+}$cells were absent from the jejunum of the BBdp rat but there was a marked increase in $\mathrm{CD}^{+} \mathrm{T}$ cells in BBdp lamina propria. These findings are consistent with the known effects of lymphopaenia on $\mathrm{CD}^{+} \mathrm{T}$ cells and IEL in the BBdp rat $^{46} 47$ and, together, support the idea that $\mathrm{CD}^{+} \mathrm{T}$ cells may be responsible for the associated enteropathy. A striking finding from the immunohistological analysis was the decreased numbers of class II $\mathrm{MHC}^{+} \mathrm{DC}$ in BBdp rat mucosa, perhaps indicating abnormal maturation or activation of intestinal DC in these animals. There have been of reports of abnormal maturation and functions of DC in both BBdp rats ${ }^{46} 47$ and NOD mice ${ }^{48-51}$ (our unpublished observations). Thus it would be interesting to confirm our findings and to determine if DC dysfunction plays a role in the enteropathy or diabetes in the $\mathrm{BB}$ rat.

The fact that enteropathy is independent of diabetes raises the question of why enteropathy did not occur in BBc rats that share a large proportion of their genes. ${ }^{52}$ One of the best understood genetic differences between the two strains is the presence of the lymphopaenia (lyp) gene in diabetes prone $\mathrm{BB}$ rats and it is possible that diabetes and enteropathy in diabetes prone $\mathrm{BB}$ rats are independent consequences of the lyp mutation. The genetic association between lymphopaenia, diabetes, and enteropathy needs to be addressed in appropriate congenic BB rat lines. Depending on the results of this analysis, it may be that genetic susceptibility to enteropathy is one of the multiple factors that contributes to the pathogenesis of TID in humans and it will be interesting to determine whether this feature is present in all experimental models of TID.

In conclusion, this study has demonstrated that diabetes prone $\mathrm{BB}$ rats have a coeliac disease-like enteropathy that is established from an early age, providing further support for a link between the gut and the pathogenesis of TID. The fact that diet and thymectomy, two external factors that have been shown to alter the course of diabetes, had no effect on gross measures of enteropathy suggests that these interventions do not prevent diabetes by restoring or preventing gut damage. This does not rule out the possibility that enteropathy is a constitutive trait that facilitates the development of diet induced diabetes. Future analysis of the pathogenesis of enteropathy may provide a useful clue to the genetic factors predisposing to TID.

\section{ACKNOWLEDGEMENTS}

This work was funded by the Juvenile Diabetes Research Foundation, the Canadian Institutes of Health Research, Ontario Research and Development Challenge Fund, Canada Foundation for Innovation, and Health Canada. Thanks to Mr J Souligny and Mr D Patry of the Animal Resources Division, Health Canada, for animal care, and Ms H Gruber for technical support. We thank Flip Klatter for performing the thymectomies in Groningen, the Netherlands, where the experimental work was supported by grants from the Dutch Diabetes Foundation (DFN98.148 and DFN01.024). Thanks to Robin Reid, Department of Pathology, University of Glasgow, for assistance with histology studies.

\section{Authors' affiliations}

S Graham, A Mc I Mowat, Department of Immunology and Bacteriology, University of Glasgow, Western Infirmary, Glasgow, UK
P Courtois, W J Malaisse, Laboratory of Experimental Hormonology, Brussels Free University, Brussels, Belgium

J Rozing, Department of Cell Biology, Section Immunology, Faculty of Medical Sciences, University of Groningen, Groningen, the Netherlands F W Scott, Molecular Medicine Program, Ottawa Health Research Institute, University of Ottawa, Ottawa, Ontario, Canada

\section{REFERENCES}

1 Akerblom HK, Knip M. Putative environmental factors in type 1 diabetes. Diabetes Metab Rev 1998;14:31-67.

2 Scott FW. Food-induced type I diabetes in the BB rat. Diabetes Metab Rev 1996; 12:341-59.

3 Scott FW, Mongeau R, Kardish $M$, et al. Diet can prevent diabetes in the BB rat. Diabetes 1985;34:1059-62.

4 Elliott RB, Martin JM. Dietary protein: a trigger of insulin-dependent diabetes in the BB rat? Diabetologia 1984;26:297-9.

5 Malkani S, Nompleggi D, Hansen J, et al. Dietary cow's milk protein does not alter the frequency of diabetes in the BB rat. Diabetes 1997;46:1130-40.

6 Beales $P$, Elliott RB, Flohe W, et al. A multi-centre, blinded international trial of the effect of $A(1)$ and $A(2)$ beta-casein varients on diabetes incidence in two rodent models of spontaneous type 1 diabetes. Diabetologia 2002;45:1240-6.

7 Coleman DL, Kuzava JE, Leiter EH. Effect of diet on incidence of diabetes in nonobese diabetic mice. Diabetes 1990;39:432-6.

8 Elliott RB, Reddy SN, Bibby NJ, et al. Dietary prevention of diabetes in the non-obese diabetic mouse. Diabetologia 1988;31:62-4.

9 Karges W, Hammond-McKibben D, Cheung RK, et al. Immunological aspects of nutritional diabetes prevention in NOD mice: a pilot study for the cow's milk-based IDDM prevention trial. Diabetes 1997;46:557-64.

10 Klemetti P, Savilahti E, llonen J, et al. T-cell reactivity to wheat gluten in patients with insulin-dependent diabetes mellitus. Scand J Immunol 1998;47:48-53.

11 MacFarlane A, Burghardt K, Kelly J, et al. A type 1 diabetes-related protein from wheat (Triticum aesstivum). cDNA clone of a wheat storage globulin, Glbl, linked to islet damage. J Biol Chem 2003;278:54-63.

12 Sigurs N, Johansson C, Elfstrand PO, et al. Prevalence of coeliac disease in diabetic children and adolescents in Sweden. Acta Paediatr 1993:82:748-51.

13 Carlsson AK, Axelsson IE, Borulf SK, et al. Prevalence of IgA-antiendomysium and IgA-antigliadin autoantibodies at diagnosis of insulin-dependent diabetes mellitus in Swedish children and adolescents. Pediatrics 1999;103:1248-52.

14 Hansen D, Bennedbaek FN, Hansen LK, et al. High prevalence of coeliac disease in Danish children with type I diabetes mellitus. Acta Paediatr 2001;90:1238-43.

15 Schuppan D, Hahn EG. Celiac disease and its link to type 1 diabetes mellitus. J Pediatr Endocrinol Metab 2001;14(suppl 1):597-605.

16 Bao F, Yu L, Babu S, et al. One third of HLA DQ2 homozygous patients with type 1 diabetes express celiac disease-associated transglutaminase autoantibodies. J Autoimmun 1999;13:143-8.

17 Bazzigaluppi E, Lampasona V, Barera G, et al. Comparison of tissue transglutaminase-specific antibody assays with established antibody measurements for coeliac disease. J Autoimmun 1999;12:51-6.

18 Lie BA, Sollid LM, Ascher H, et al. A gene telomeric of the HLA class I region is involved in predisposition to both type 1 diabetes and coeliac disease. Tissue Antigens 1999:54:162-8

19 Saukkonen T, Savilahti E, Reijonen $\mathrm{H}$, et al. Coeliac disease: frequent occurrence after clinical onset of insulin-dependent diabetes mellitus. Childhood Diabetes in Finland Study Group. Diabetes Med 1996;13:464-70.

20 Carratu R, Secondulfo M, de Magistris L, et al. Altered intestinal permeability to mannitol in diabetes mellitus type I. J Pediatr Gastroenterol Nutr $1999 ; 28: 264-9$.

21 Meddings JB, Jarand J, Urbanski SJ, et al. Increased gastrointestinal permeability is an early lesion in the spontaneously diabetic BB rat. Am J Physiol 1999;276:G951-7.

22 Hanninen A, Taylor, C, Streeter, PR, et al. Vascular addressins are induced on islet vessels during insulitis in nonobese diabetic mice and are involved in lymphoid cell binding to islet endothelium. J Clin Invest 1993:92:2509-15.

23 Hanninen A, Jaakkola I, Jalkanen S. Mucosal addressin is required for the development of diabetes in nonobese diabetic mice. J Immunol 1998;160:6018-25.

24 Yang XD, Michie SA, Tisch R, et al. A predominant role of integrin alpha 4 in the spontaneous development of autoimmune diabetes in nonobese diabetic mice. Proc Natl Acad Sci U S A 1994;91:12604-8.

25 Hanninen A, Salmi M, Simell O, et al. Mucosa-associated ( $\beta$ 7-integrin high) lymphocytes accumulate early in the pancreas of NOD mice and show aberrant recirculation behavior. Diabetes 1996;45:1173-80.

26 Yang XD, Sytwu HK, McDevitt HO, et al. Involvement of beta 7 integrin and mucosal addressin cell adhesion molecule-1 (MAdCAM-1) in the development of diabetes in obese diabetic mice. Diabetes 1997;46:1542-7.

27 Paronen J, Klemetti P, Kantele JM, et al. Glutamate decarboxylase-reactive peripheral blood lymphocytes from patients with IDDM express gut-specific homing receptor $\alpha 4 \beta 7$-integrin. Diabetes 1997;46:583-8.

28 Rao GN. New nonpurified diet (NTP-2000) for rodents in the National Toxicology Program's toxicology and carcinogenesis studies. J Nutr 1997; 127:842S-6.

29 Clarke RM. Mucosal architecture and epithelial cell production rate in the small intestine of the albino rat. J Anatomy 1970;107:519-29. 
30 Mowat AMcl, Ferguson A. Intraepithelial lymphocyte count and crypt hyperplasia measure the mucosal component of the graft-versus-host reaction in mouse small intestine. Gastroenterology 1982;83:417-23.

31 Dahlqvist A. Disaccharidases. In: Bergmeyer HU, eds. Methods of enzymatic analysis. New York: Academic Press, 1974:916-22.

32 Bozeman PM, Learn DB, Thomas EL. Assay of the human leukocyte enzymes myeloperoxidase and eosinophil peroxidase. J Immunol Methods 1990;126:125-30.

33 Howard JC, Scott DW. The role of recirculating lymphocytes in the immunological competence of rat bone marrow cells. Cell Immunol 1972:3:421-9.

34 Marsh M. Grains of truth: evolutionary changes in small intestinal mucosa in response to environmental antigen challenge. Gut 1990;31:111-14.

35 Like AA, Kislauskis E, Williams RR, et al. Neonatal thymectomy prevents spontaneous diabetes mellitus in the BB/W rat. Science 1982;216:644-6.

36 Garside P, Grencis RK, Mowat AMcl. T lymphocyte dependent enteropathy in murine Trichinella spiralis infection. Parasite Immunol 1992;14:217-25.

37 Mowat AMcl. Intestinal graft-versus-host disease. In: Ferrara JM, Deeg, JH, Burakoff SJ, eds. Graft versus host disease, 2nd edn. New York: Marcel Dekker, 1997:307-84.

38 Ferguson A. Models of immunologically-driven small intestinal damage. In: Marsh MN, eds. Immunopathology of the small intestine. Chichester: John Wiley and Sons, 1987:225-52.

39 Garside $\mathbf{P}$, Reid S, Steel $M$, et al. Differential cytokine production associated with distinct phases of murine graft-versus-host reaction. Immunology 1994:82:211-14.

40 Nilsen $\mathrm{EM}$, Jahnsen $\mathrm{FL}$, Lundin $\mathrm{KE}$, et al. Gluten induces an intestinal cytokine response strongly dominated by interferon gamma in patients with celiac disease. Gastroenterology 1998;115:551-63.

41 Sollid LM. Coeliac disease: dissecting a complex inflammatory disorder. Nat Rev Immunol 2002;2:647-55.
42 Scott FW, Rowsell P, Wang GS, et al. Oral exposure to diabetes-promoting food or immunomodulators in neonates alters gut cytokines and diabetes. Diabetes 2002;51:73-8

43 Strober W, Fuss IJ, Blumberg RS. The immunology of mucosal models of inflammation. Annu Rev Immunol 2002;20:495-549.

44 Dvorcakova M, Macejova D, Pallet V, et al. Transglutamines and endocrine system (minireview). Endocr Regul 2002;36:31-6.

45 Kukreja A Cost G, Marker J, et al. Multiple immuno-regulatory defects in type-1 diabetes. J Clin Invest 2002;109:131-40.

46 Angelillo M, Greiner DL, Mordes JP, et al. Absence of RT6+ T cells in diabetes prone biobreeding/Worcester rats is due to genetic and cell developmental defects. J Immunol 1988;141:4146-51.

47 Ramanathan S, Poussier P. BB rat lyp mutation and type 1 diabetes. Immunol Rev 2001;184:161-71.

48 Prasad SJ. Cell-intrinsic effects of non-MHC NOD genes on dendritic cell generation in vivo. Int Immunol 2002;14:677-84.

49 Vasquez AC, Feili-Hariri M, Tan RJ, et al. Qualitative and quantitative abnormalities in splenic dendritic cell populations in NOD mice. Clin Exp Immunol 2004; 135:209-18.

50 Feili-Hariri M, Morel P. Phenotypic and functional characteristics of BMderived DC from NOD and non-diabetes-prone strains. Clin Immunol $2001 ; 98: 130-42$.

51 Strid J, Lopes L, Marcinkiewicz J, et al. A defect in bone marrow derived dendritic cell maturation in the nonobesediabetic mouse. Clin Exp Immunol $2001 ; 123: 375-81$

52 Mordes JP, Bortell R, Groen H, et al. Autoimmune diabetes mellitus in the BB rat. In: Sima A, Shafrir E, eds. Frontiers in animal diabetes research, a primer on animal models of diabetes. Reading, UK: Harwood Academic Publishers, 2001:67-78.

\section{EDITOR'S QUIZ: GI SNAPSHOT}

\section{A waxing and waning skin rash}

\section{Clinical presentation}

A 72 year old Caucasian female attended the Department of Dermatology with an 11 year history of elevated blood sugar ( $145 \mathrm{mg} / \mathrm{dl}$ ) (fig 1). A computerised tomogram was performed (see fig 2). The patient was scheduled for surgery, and a distal pancreatectomy and splenectomy were performed. Examination of the rest of the abdomen was normal. The patient is free of disease after 24 month of follow up and dermal changes cleared seven days after surgery.

\section{Question}

What does computerised tomograpy show and how does it explain the longstanding rash?

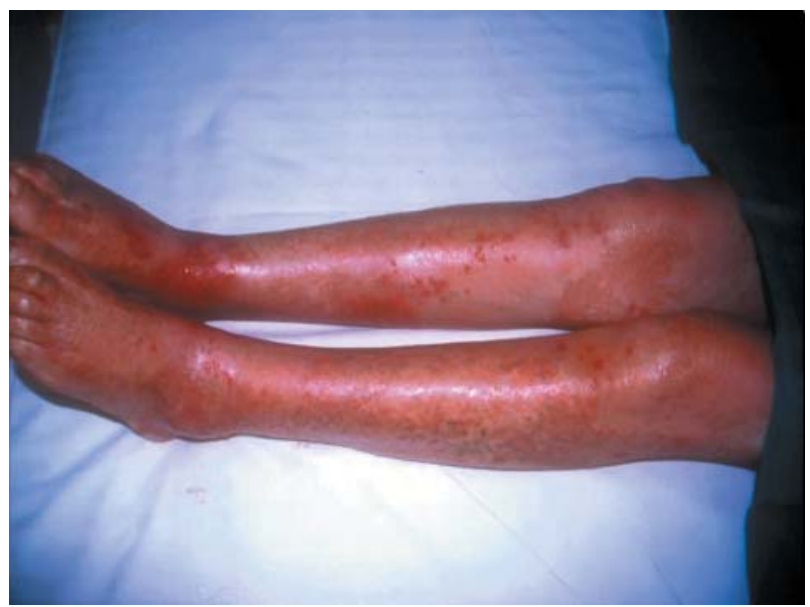

Figure 1

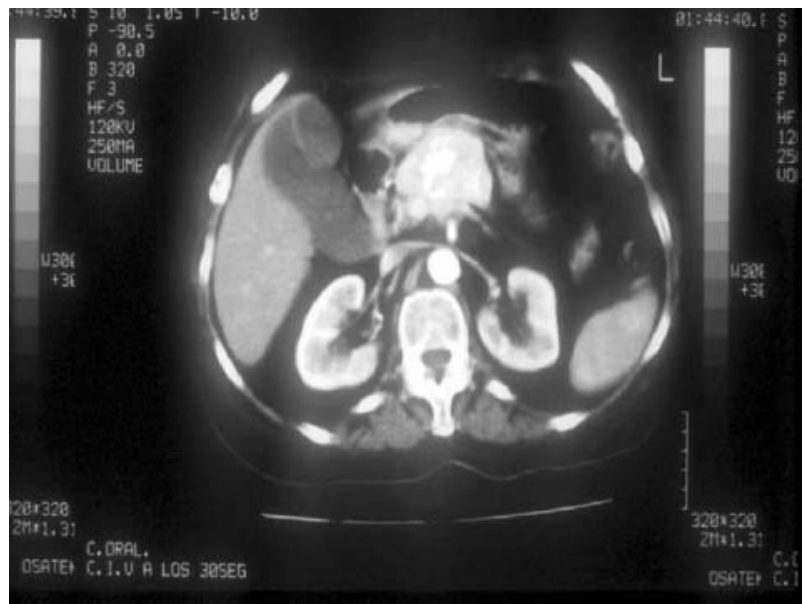

Figure 2 Computerised tomography of the abdomen.

See page 1451 for answer

This case is submitted by:

M Echenique-Elizondo, S de D Jorge Basque Country University School of Medicine, San Sebastián, Spain

Correspondence to: Professor M Echenique-Elizondo, Basque Country University, School of Medicine, Paseo Dr Beguiristain, 105, 20014 San Sebastián, Spain; gepecelm@sc.ehu.es doi: $10.1136 /$ gut.2003.035121 